Sociohistórica

ISSN: $1852-1606$

publicaciones@fahce.unlp.edu.ar

Universidad Nacional de La Plata

Argentina

\title{
“(Des)aparición y después. Entre el arrasamiento y la (re)construcción de los espacios de interacción"
}

\author{
Lampasona, Julieta \\ "(Des)aparición y después. Entre el arrasamiento y la (re)construcción de los espacios de interacción" \\ Sociohistórica, núm. 46, 2020 \\ Universidad Nacional de La Plata, Argentina \\ DOI: https://doi.org/10.24215/18521606e114
}

Atribución no comercial compartir igual (CC BY-NC-SA) 4.0 


\section{“(Des)aparición y después. Entre el arrasamiento y la (re)construcción de los espacios de interacción”}

\section{'(Des)appearance and after. Between razing and (re)construction of interaction spaces'}

Julieta Lampasona

DOI: https://doi.org/10.24215/18521606e114

Centro de Investigaciones Sociales - CONICET / Instituto

de Desarrollo Económico y Social / Núcleo de Estudios sobre

Memoria, Argentina

julieta.lampasona@gmail.com

Recepción: 14 Mayo 2019

Aprobación: 13 Marzo 2020

Recepción: 14 Mayo 2019

Aprobación: 13 Marzo 2020

\section{Resumen:}

La desaparición forzada de personas en la Argentina produjo múltiples rupturas psicosociales. En el caso de los sobrevivientes de los Centros Clandestinos de Detención (CCD), la vida con posterioridad a la (propia) desaparición se fue desplegando con pesares, miedos y modalidades diversas de persistencia de la violencia vivida. A partir del análisis de entrevistas en profundidad a sobrevivientes de los CCD, en este artículo se abordan las primeras reconfiguraciones producidas en los espacios de acción e interacción, haciendo foco en la desarticulación de los espacios relacionados con la acción política y las (re)construcciones de nuevos entramados, vinculados principalmente con ámbitos privados de la vida cotidiana, como la familia y el estudio.

Palabras clave: Desaparición, Sobrevivientes, Espacios de interacción.

\section{Abstract:}

Enforced disappearance in Argentina produced multiple psycho-social ruptures. In the case of the survivors of the Clandestine Detention Centers (CCD), life after (own) disappearance was deployed with regrets, fears and different forms of violence's persistence. From the analysis of in-depth interviews realized to CCD's survivors, this article deals with the first reconfigurations produced in the spaces of action and interaction, focusing on the disarticulation of the spaces related to political action and the (re)constructions of new interaction frameworks, mainly linked with private areas of daily life, such as family and study.

KEYWORDS: Disappearance, Survivors, Interaction spaces.

\section{1) INTRODuCCión}

La desaparición forzada de personas, desplegada en la Argentina durante 1975-1983, ${ }^{1}$ produjo un cúmulo de rupturas psicosociales cuya vigencia se sostiene en el presente. En el caso específico de los sobrevivientes de los Centros Clandestinos de Detención (CCD), ${ }^{2}$ la vida con posterioridad a la (propia) desaparición estuvo atravesada por múltiples formas de persistencia de la violencia vivida que afectaron al/los sujeto/s en la dimensión de su propia subjetividad avasallada ${ }^{3}$ como así también en lo referido a sus principales ámbitos de acción, interacción y pertenencia -vinculados, fundamentalmente, con la militancia política, social y/o sindical ${ }^{4}$-. No obstante ello, los sujetos fueron poco a poco - y como pudieron- reinscribiéndose en nuevos entramados intersubjetivos y repertorios de acción que coadyuvaron, en mayor o menor medida, en formas incipientes de elaboración y reposicionamiento subjetivo.

En el marco de un campo de estudios que reconoce sus principales antecedentes en las experiencias del exterminio nazi y el caso argentino, ${ }^{5}$ en este artículo, abordaré las oscilaciones producidas entre la desarticulación de los espacios de acción (política) y la (re)construcción de esos nuevos (o viejos) entramados con el objeto de analizar sus implicancias en las trayectorias de vida. A modo de hipótesis, sostendré que al tiempo que las diversas formas de aislamiento y/o retraimiento que acuciaron al/los sujeto/s en los momentos 
posteriores a la liberación fueron reforzando los efectos de la experiencia vivida, ${ }^{6}$ el repliegue sobre los espacios afectivos más próximos - como la familia-, y/u otros ámbitos privados de interacción -como el estudio, ${ }^{7}-$ dio lugar a formas de sostén, resguardo y amparo que apuntalaron al/los sujeto/s -al menos en los primeros tiempos- y viabilizaron con ello modalidades incipientes de reafirmación subjetiva y proyección a futuro.

A partir del análisis de historias de vida de sobrevivientes de CCD residentes, al momento de las entrevistas, en la Ciudad de Buenos Aires y el Gran Buenos Aires, ${ }^{8}$ estructuraré la exposición en diferentes apartados. En el primero, me abocaré al momento de des-articulación social y política que se anuda a la (propia) desaparición, haciendo foco en las implicancias subjetivas del cúmulo de des-vinculaciones previas y posteriores a la experiencia límite. Luego, abordaré la re-configuración de esos nuevos entramados relacionales que, vinculados al espacio íntimo y/o privado de la vida cotidiana, operaron -al menos en los primeros tiempos- como los ámbitos primarios de sostén y cobijo.

\section{2) De RUPTURAS y DES-VINCUlaciones}

Como se anticipó, las trayectorias de vida que componen este estudio hablan de profundas rupturas: de los espacios de acción, de lazos, de proyectos de vida, de construcciones identitarias. Mayoritariamente, estos quiebres se vinculan con los momentos posteriores a la propia desaparición, al tiempo que algunas voces dan cuenta también de rupturas previas que remiten a desencuentros múltiples con espacios de pertenencia vínculos familiares, amistades y/o ámbitos políticos-, ${ }^{9}$ dando espesura a un derrotero de desvinculaciones que anuncia pesadas cargas. Ahora, ¿en qué consiste ese cúmulo des-vinculaciones que se producen antes y después del atravesamiento del CCD? ¿Cuáles son las especificidades de esas rupturas y, también, sus posibles solapamientos? Y, en todo caso, ¿qué significación asumen en los cursos vitales, trastocados y reconfigurados por la (propia) desaparición?

\section{1) Aislamientos previos}

La consolidación -hacia mediados de los años 70- de los procesos de hostigamiento y persecución política de los sectores movilizados del campo popular y, particularmente, los procesos de terror desplegados con posterioridad al golpe militar de marzo de 1976, configuraron el escenario de múltiples rupturas, distanciamientos y desencuentros que antecedieron a la propia desaparición. En efecto, el peligro y la posibilidad de la muerte fueron complejizando las condiciones para la militancia política y propiciando, de manera acentuada, la reducción y/o el cercenamiento de los espacios cotidianos de encuentro, participación y socialización. Como señalan las autoras de Ese infierno:

La militancia se había transformado. Ya no era esa experiencia plena, semejante a la felicidad, que a todos nos había embargado: a partir de 1976 el peligro, la tortura, la muerte, se sentían cada vez más cerca... estuvo marcada por el cansancio, el desamparo, el miedo. El terror cerraba las puertas que antes se abrían para los militantes. Estaban cercados, golpeados por las desapariciones casi diarias de los que querían (Actis, Aldini, Gardella, Lewin, y Tokar, 2001, p. 37).

$\mathrm{Al}$ respecto, coinciden también otros testimonios; entre ellos, el de Pilar Calveiro:

La militancia después del golpe del 76 ya es otra cosa (...). Es ya una situación de estar... arrinconado. Y yo tenía bastante
claro que nos iban a hacer mierda. Y sin embargo, era persistir en una apuesta (...), creo que estaba la cosa de los compañeros
muertos (...). Un pedazo de esperanza de salvar algo (...). Tu mundo se había convertido, se había acortado a esta militancia,
de los compañeros (Memoria Abierta, Testimonio de Pilar Calveiro, Buenos Aires, 2006).

En su estudio sobre las localidades de La Plata, Berisso y Ensenada, la socióloga María Maneiro (2005) profundiza sobre las rupturas -familiares, laborales, sociales y políticas- anudadas a la vida en clandestinidad, por un lado, y la proximidad cotidiana de la muerte, por el otro. En este sentido -señala- los procesos 
de desaparición se solapan e imbrican con un cúmulo de des-vinculaciones previas que fueron marcando y mellando la vida cotidiana de los sujetos, sus propias familias y entornos. La amenaza de muerte comenzaba a producir el repliegue, el aislamiento, al tiempo que configuraba un nuevo espacio de incertidumbre y desamparo. Los ámbitos de militancia y de referencia comenzaban a cercenarse, a reducirse, y así emerge en los testimonios:

Y ahí, obviamente, (...) se fueron... ireduciendo nuestros espacios! Pero reduciendo mucho nuestros espacios. Había una situación... en la que... ¡lo que prevalecía era tu seguridad! Entonces vos no podías ir a un lugar, y volver tarde... E ir a un lugar donde iba a haber militantes de otras agrupaciones, o de otros frentes, o de otras tendencias. Vos estabas ahí y con los que te juntabas era con tus compañeros de ámbito... O sea, toda tu posibilidad de conocer otra gente, ¡estaba muy reducida! ¿No? Por cuestiones de seguridad (Miriam, comunicación personal, 30 de mayo de $2011^{10}$ ).

Y bueno, y tratábamos, en lo posible, de conectarnos con otros que estuvieran... Pero, claro, al no saber dónde vivían los demás, viste, como nosotros estábamos todos compartimentados, sólo te podías ver con los que sabías dónde vivían o tenías un teléfono. [Con un tono más apagado, pensativo] Y, sí, había una cosa así como de... soledad (Susana, comunicación personal, 29 de noviembre de $\left.2011^{11}\right)$.

Y en la Facultad ya venía una época muy difícil. Era en el... 78. ¡Y no tengo grupo, en la Facultad! Porque en ese momento mis compañeros estaban..., no había prácticamente muchos compañeros en mi Facultad, que era de Psicología, algunos se habían ido, otros estaban..., eh..., no sé haciendo qué, trabajando. No tengo grupo. Y empiezo medio a alejarme también, porque... [pensativa, con un tono bajo] no sé qué pasó... [Con agobio] En el 76 habían caído unos, en el 77 otros... Nosotros que vivíamos en una pensión, que me iba para el otro lado, que vivía con no sé quién. Todo era un lío... Este..., estoy un poco descolgada del grupo, no... (...). Y había mucho miedo. Mucha represión y todo se hacía con mucho temor... [Baja el tono de voz] En ese interín..., nada, ya me alejé un poquitito pero me llevaron, así que no..., no sé. (...) Sé que estaba como descolgada en ese momento. De la militancia, pasar de ser algo muy importante a sentir que ya me había quedado sin un grupo permanente de referencia (Nieves, comunicación personal, 10 de abril de $2012^{12}$ ).

Ese mundo de referencia comenzaba, así, a desmoronarse. A partir de entonces -señala Maneiro- la vida de los militantes comenzaba a articularse, fuertemente, en torno a la supervivencia (2005, p. 92) como figura que condensa el golpe y el cercenamiento abrupto que produce esa nueva realidad de muerte/desaparición. En este marco, los tiempos se acortaban ante la inmediatez de ese mundo relacional cercenado y, fundamentalmente, ante la amenaza concreta de la muerte posible. Con ello, comenzaba a transformarse también ese horizonte de sentido que sostenía el propio hacer político. Frente a este acotamiento, los relatos se van desplazando desde un tiempo de proyección -individual y colectiva- configurado en torno de la militancia hacia un presente continuo donde la amenaza de muerte cobra centralidad y emerge, acechante, en su propia evocación.

\section{2) La "soledad" del después. Nuevos pliegues del entrampamiento}

Producto del terror y la desaparición, entonces, el mundo de la militancia -aquel que funcionaba como espacio de pertenencia y proyección a futuro- se había ido cercenando: gran parte de "los compañeros" no estaban ya -muchos habían desaparecido, otros se habían exiliado, otros habían simplemente abandonado la militancia- y los espacios conjuntos de acción se habían ido desarticulando, mayoritariamente. Y en ese marco de persecución, desarticulaciones y "caídas", ${ }^{13}$ se produjo el propio secuestro y desaparición.

Una vez liberados, el pesar por la (propia) desaparición y posterior sobrevida se reforzaba en y con la desarticulación de ese mundo de afectividades, solidaridades y cotidianeidad, que se había configurado en torno de la militancia. De modos diversos, el resquebrajamiento de los espacios intersubjetivos y los modos de acción vinculados a la práctica política cobra espesura en los relatos dando cuenta de la fuerza disruptiva del secuestro y la (propia) desaparición y así, como producto del terror y el peligro -en plena dictadura-- o como parte de las (im)posibilidades y/o disposiciones subjetivas de cada caso, el relato de esa (sobre)vida comienza a articularse con la preeminencia de un yo avasallado que emerge como contrapunto del desdibujamiento de las instancias colectivas y las proyecciones del sujeto. ${ }^{14}$ Volvamos a las entrevistas. 
En el caso de Susana, los tiempos posteriores a su liberación estuvieron fuertemente vinculados al nacimiento de su hijo y la búsqueda de su compañero desaparecido. En nuestras conversaciones, así recordaba los primeros momentos en "libertad" ${ }^{15}$

E: ${ }^{16}$ ¿Y cuando llegaste a lo de tu mamá, en esos días que pasaron, qué empezaste a hacer?

S: Y yo llegué a lo de mi mamá y... Y, bueno, mi mamá vivía en un departamento de 2 ambientes, con mi hermano, que tiene 3 años más que yo, eh, que vivía ahí. ¡Y mi abuela! Imaginate [sonríe]. Y yo llegué. Yo lo que empecé a hacer es..., eh..., yo estaba... La verdad es que... en esa época estaba muy sola, porque todos mis amigos no estaban. V. [su amiga] estaba en el exilio, porque se habían llevado a su hermana... ¡Yo no tenía a nadie, porque no tenía a nadie! O sea, todos mis compañeros desperdigados...

\section{Más adelante señalaba entre lágrimas:}

No, no, no... Yo estaba como..., no... No, no... Era como... O sea, que nunca pude ser la misma, ¿entendés? No, ¡no era alegría por nada! No. No podía decir... Para mí eso no era libertad, sabiendo que estaban secuestradas las chicas ahí [en relación a sus compañeras de cautiverio, que continúan desaparecidas]. Eh... No, era como que no... Es un lugar que no tiene retorno, no sé. Hay algo que quedó ahí. Y, sí, yo estaba contenta de ver a mi mamá, a mi abuela, pero... ¡nada tenía sentido! No te puedo explicar... Era como... (...) Era muy difícil vivir, porque ahí me di cuenta que nadie... ique todo el mundo estaba en cualquiera! ( Susana, comunicación personal, 29 de noviembre de 2011).

La ausencia de ese mundo de interrelación construido, personificada fundamentalmente en la figura de su compañero y sus amistades, junto con la suerte corrida por sus compañeras de cautiverio, redoblaban los pesares y la sensación de soledad. Esas rupturas, esas ausencias y dolores desinvestían de sentido su propia (sobre)vida y traían la certeza de una vivencia, de un lugar de "no retorno" a partir del cual no volvería a "ser la misma”.

En el caso de Delia, se advierte también esa soledad de los tiempos posteriores. ${ }^{17}$ El cuidado de sus hijos pequeños, la ausencia de su compañero desaparecido, la muerte de su padre y la enfermedad de su pequeña hija -producto de las secuelas que la tortura había generado en su embarazo durante el primero de sus dos secuestros- configuraban un contexto complejo que potenciaba la ruptura de ciertos vínculos:

Eran años de terror, de silencio, de estar pendiente que no sabés a dónde caer, ni con quién hablar, ni qué decir, ni poder hablar con nadie de nada. Me preguntaban por el padre de mi hijo, que lo había abandonado, tuve también que tener toda una historia armada para contarle a todo el mundo y hablar lo menos posible de todo. Así que fueron años muy duros (...).Y sin poder compartir con nadie porque a vos, es tu mundo, y las conversaciones eran, con las docentes, con todo el mundo había un... Como que uno se armó de una coraza para todo, no solamente para poder seguir viviendo, sino en las relaciones con los demás, porque no sabías ni con quién estabas hablando, ni lo que decías adónde llegaba. (...) Y era todo oscuro.

En los años siguientes, los espacios de relación se habían resquebrajado profundamente:

E: ¿En ese contexto seguías viendo a tus amigos o era más difícil...?

D: Y ahí era muy difícil. Bah, seguí viendo a los que yo tenía, de todo el grupo que éramos, a dos amigas, que nos seguimos viendo ahora. Eh, a esta amiga que el marido era el compañero de trabajo y de militancia de M. [su marido]. Después ellos con el tiempo se separaron y con ella nos seguimos viendo permanentemente aún hoy. Y mi otra amiga, en abril, mayo del 77 también fue secuestrada, ella estuvo en Mansión Seré, 14 días, también la largaron, fue una detención fea. Ella después se fue para España. Pero cuando volvió también nos seguimos viendo. Pero en aquellos trances con la que me veía era con una de mis amigas, con la cual siempre... que tenía dos nenes de las edades de mi hijos más o menos. (...) Con otros no, porque algunos se fueron, eh, o no estaban en el barrio. Después nos fuimos reencontrando, pero en esos años no había relación con nadie (Delia, comunicación personal, 5 de agosto de 2014).

Las vicisitudes de la vida privada cobraron centralidad durante los años posteriores a los secuestros, subsumiéndola en un profundo repliegue sobre el núcleo familiar que persistió hasta entrados los años 80 y se sostuvo, al menos, hasta la muerte de su niña, a mediados de esa década.

Militante de la Juventud Guevarista, Julián había sido secuestrado a finales de abril de 1976 y, luego de permanecer recluido en lo que posteriormente pudo identificar como Coordinación Federal, fue puesto a 
disposición del PEN. Tras largos meses en el Penal de La Plata, en diciembre de ese año fue liberado. En su caso, la tortura le había dejado graves secuelas físicas que, una vez en libertad, acarrearon un conjunto de operaciones que lo mantuvieron en extremo reposo. Esta situación particular, en un contexto en el que persistían las desapariciones, dio lugar a un profundo aislamiento, y a un repliegue sobre sus vínculos más íntimos. A partir de entonces, se iniciaría una nueva etapa en su vida, absolutamente escindida de los vínculos previos y de la actividad política:

E: ¿Y volviste a frecuentar a tus compañeros del colegio, de militancia?

J: No. No. En absoluto. No, porque... Por ejemplo, hubo, eh... posterior a mi libertad, digamos, fueron saliendo en libertad otros pibes, que se iban al exilio. (...) Y evitábamos todo tipo de... O sea, te enterabas, por ahí te hablabas por teléfono, pero no salías... a encontrarte, ¿entendés? No era una cosa que vos podías... hacer sociales, digamos. O expandirte, decir: " $i A h$, vamos a festejar, que salimos...!”. No, era, eh... Es increíble, pero era algo que... jenvolvía todo! Ese clima denso y de terror, este... parecía como naturalizado. O sea, estaba incorporado a la cotidianeidad. (...) Digamos, era como si un mundo, que vos tenías, desapareció.

En este sentido, la reclusión propia de su dolencia hizo serie así con profundas desvinculaciones, que traerían ante todo la sensación -aún vigente- de un "mundo arrasado", "desaparecido":

Yo tengo el pensamiento consciente de mi mundo desaparecido, simplemente... ¡hay cosas que no están más! [Hace una pequeña pausa]. No, no, no hay, eh... Eh, el efecto que más, digamos, que yo mejor puedo... pienso que transmite, es el tema de algo... ¡Tierra arrasada! Algo arrasado. Algo que, viste, ¡que estaba y no está más!.

Julián retomó sus estudios de Economía en el año 78, recibiéndose en 1982. Y lo hizo -señala- "en un cono de sombra", "en una especia de isla", como parte de un "deambular" posterior a la (propia) desaparición. ${ }^{18}$ Un transcurrir lo cotidiano que obliteraba, "negaba” y silenciaba ese pasado inmediato: “(...) ese deambular parece que tiene una lógica, una coherencia. Está totalmente sumergido en una situación de, [baja el tono] de oscuridad y de silencio de lo que seguía pasando... Y de negación”. Su mundo de relaciones previas, fuertemente vinculadas a la política, se vio sacudido, devastado. Preso de esa devastación, como "aturdido", su vida previa permanecía negada y soterrada - por largos años- en el devenir de lo cotidiano. Una cotidianeidad nueva se delineaba, escindida plenamente del “antes” de la (propia) desaparición:

Porque imaginate que yo en el 77, si bien estaba muy... en un cono de sombra, guardado, retraído (...), estaba básicamente aislado. Estaba muy, muy metido en la casa, muy..., con mucho miedo. (...) Y a partir de eso, digamos, mi mundo se empieza a armar como desconociendo toda mi vida anterior. (...) Digamos, era como..., como si un mundo que vos tenías... desapareció. Bueno, la palabra..., pero implosionó, explotó por el aire. Y había otro mundo, vamos a llamarlo de..., el mundo no político, el mundo apolítico, el mundo del trabajo... O de la familia, de la novia de los 15 años (...). Vos fijate mi deambular: voy a la facultad, más o menos. Voy, pero sin mucho, digamos, entusiasmo. Para ponerle un término. Como que yo ya estaba como... ¡limado! Fisurado, limado, a media máquina. Aun así, fui positivo, digamos, fui para adelante. Pero ir para adelante no implica que estás bien encaminado. Simplemente estás yendo para adelante. No estás mirando, ni evaluando, ni siendo muy crítico. Estás en una huida hacia adelante, digamos. No sabés de qué estás huyendo, pero... [pequeña pausa]. Eh..., ¡empezás ese deambular!

(...) Y después, con los años empezar a... [parece trabarse, como buscando las palabras] a construir un relato de mi vida, de mi... De, de... de mi deambular a partir del episodio de la desaparición. [Hace una pequeña pausa].

O sea que tiene, digamos, para ordenar un poco el relato, tiene un montón de componentes. O sea, la militancia previa, la detención, la tortura, las fracturas, la recuperación física. El ir a la universidad... como una sombra. Empezar a intentar aparecer un poco y después, después recular, retraerme. Entrar en un cono de sombra. Eh... tener una vida que era una vida, digamos, de alguna manera..., de un mundo... [parece trabarse nuevamente, como buscando las palabras] que, digamos, que para mí... ¡era un exceso de vida! ¿Me entendés? ¡Porque yo no podía creer que tenía esa posibilidad de volver a vivir! Y, bueno, volviendo al tema de la facultad, que era mi conexión con el mundo más real..., a medias, eh... (...), como una sombra, el hecho de haberme recibido..., sin saber bien ya para qué, ¿̇me entendés? Una especie de..., de un tránsito degradado del estudio hacia el título de economista (Julián, comunicación personal, 26 de abril de 2011).

Su mundo conocido había sido "arrasado" y a eso se anudaban, sin embargo, nuevos espacios de socialización. ${ }^{19}$ 
La historia de Margarita expone, también, la profundidad de las rupturas y de esa soledad posterior. Alejada de su Tucumán natal -donde había sido secuestrada en mayo de $1975^{20}$, los primeros años de insilio en Buenos Aires fueron de un profundo pesar y de un fuerte sentimiento de culpa por la suerte corrida por su familia: ${ }^{21}$ desmembrada entre Tucumán y Buenos Aires, la situación de precariedad y peligro y, unos años después, la sucesivas muertes de su padre y de su madre acabaron por generar en ella una sensación de "devastación". Con su marido preso y la sola ayuda de su madre, los primeros tiempos en Buenos Aires habían sido de una dureza y un aislamiento extremos. Tironeada entre el cuidado de su hijo pequeño y trabajos que alcanzaban tan solo para la subsistencia, Margarita recuerda ese período con un profundo desgarro, emocional y vincular. En 1977 su esposo - que hasta entonces permanecía preso en la provincia de Tucumánfue liberado, lo que no implicó sin embargo una mejora en las condiciones de vida. Si bien habían logrado contactarse con compañeros de Montoneros (zona Sur) y retomar cierta militancia de manera clandestina, persistía la situación de precariedad y, fundamentalmente, de terror. Los compañeros caían y la situación económica continuaba siendo muy mala; en ese contexto, incluso, habían tenido que dejar a su hijo al cuidado de una familia de conocidos, en una localidad del Gran Buenos Aires:

\begin{abstract}
¡Aparte nosotros no teníamos nada! [Comienza a hablar más rápidamente, agitada, con angustia] Porque vivíamos en pensiones, dejábamos lo que teníamos. No, no, era una cosa, un desastre. No había para comer, no había para pagar la pensión. La única que trabajaba era yo porque esa cuestión de legalidad me daba una fortaleza para buscar trabajo. Mi hijo no estaba conmigo, J. estaba en la casa de unos compañeros. [Sigue con un tono pausado, muy angustiada] Era un desastre, todo era un desastre. Un desastre total... Yo pasaba llorando todo el tiempo. No, era una cosa... Me arrepentía de haber vuelto con mi compañero porque las condiciones de existencia eran peores. (...) Los compañeros caían. Vos ibas a una cita y el compañero no... No, era una cosa... tremenda, tremenda, tremenda, tremenda, tremenda...
\end{abstract}

En julio de 1978 Margarita tuvo a su segundo hijo y con su compañero decidieron descolgarse definitivamente de la organización. A finales de ese año la familia pudo volver a unirse y, sin embargo, persistió la tristeza; en el curso de algunos meses, murió su padre y, poco tiempo después, su madre:

Así, que bueno, fue un desastre, un sufrimiento total, que ahora que yo me acuerdo, la verdad que... me parte el alma. Pero, bueno, la cuestión es que logramos sobrevivir a toda esa situación.

Y, bueno, pasó el 80... Bueno, lo más terrible vino después. En el 79, mi viejo se muere de cáncer y en el 80 se muere mi mamá. O sea que fue..., fueron 5 años mortales. No, una cosa que no, no... Bueno, por la muerte de mi mamá yo ahí ya me enfermo, empiezo a sentirme mal, como que no..., como que yo no... ¡no podía más! Viste, era una cosa que... Mi mamá muere en Buenos Aires, viene de visita y se muere. [Con un tono triste, bajo, como apagado] O sea que fue muy trágico todo..., toda esa época.

Margarita se sentía “enloquecer”. Tiempo después, en 1981, decidió estudiar Radiología en la Universidad del Salvador y dos años después pudo comenzar a ejercer la profesión. Y fue precisamente la incursión en estos nuevos entramados de relación - $\mathrm{y}$, fundamentalmente, su posterior inserción en la Asociación de Ex Detenidos Desaparecidos (AEDD)- lo que le permitió salir adelante:

Y esa estructura, diríamos, me salvó. Porque la verdad que yo estaba... devastada totalmente. Me sentía muy mal, muy mal, porque estaba con esa situación de mucha culpa por todo... El fallecimiento de mis viejos, mi hermano me hacía responsable de todo... Bueno, fue tremendo. Esos años fueron muy duros (Margarita, comunicación personal, 6 de octubre de 2011).

Como vemos, las historias van dando cuenta de diversos modos de ruptura de lo sido, de los espacios de acción e interrelación. La desarticulación del mundo conocido, la pérdida de los amores, el cercenamiento de las relaciones más próximas y de los espacios de acción política -sea por desaparición, sea por exilio, sea incluso por desconfianza de los otros- produjeron un sinfín de rupturas interpersonales y subjetivas que reconfiguraron de manera sustantiva los proyectos vitales y el espacio cotidiano del sujeto. Frente a esas descomposiciones, no obstante, se fueron conformando nuevos (o viejos) espacios y entramados de interacción que hasta el momento de la (propia) desaparición se habían visto mayoritariamente eclipsados 
por la militancia. Como veremos a continuación, esos vínculos serán evocados desde la ambigua sensación del cobijo y la pérdida, conjuntamente.

\section{3) LOS PRIMEROS RESGUARDOS. DE LA VUELTA SOBRE LOS ESPACIOS PRIVAdOS DE LA VIDA COTIDIANA Y EL RESGUARDO DE LOS VÍNCULOS MÁS PRÓXIMOS}

Desarticulados los espacios de participación y desvinculados de sus organizaciones de pertenencia, los relatos enuncian un movimiento de "repliegue" sobre otros espacios de la vida cotidiana, principalmente, aquellos que habían albergado al sujeto con anterioridad a su inserción en la escena política y que fueron objeto, luego, de fuertes tensiones: ${ }^{22}$ en primer lugar, la familia aparece como ese espacio del amparo originario que vuelve a cobijar en los momentos más solitarios; al mismo tiempo, el estudio conforma también un espacio de apelación. Aislados y/o conmocionados por la violencia vivida, los sujetos fueron encontrando allí un resguardo posible y, en este sentido, uno y otro propiciaron y/o viabilizaron procesos incipientes de recomposición subjetiva.

En el caso de Silvia, ${ }^{23}$ la militancia política había producido una serie de tensiones en el seno de su casa materna que se evidenciaban no en una discusión abierta con sus padres sino, por el contrario, desde su propio silenciamiento y/u ocultamiento. ${ }^{24}$ Sin embargo, el relato de los tiempos posteriores a su cautiverio y detención parece abrir a nuevas formas de evocación del vínculo que, inauguradas en el momento mismo de la liberación, recuperan lo que allí había de cobijo y amparo. En nuestro tercer encuentro, Silvia se dispuso a repasar un conjunto de cartas, notas y certificaciones vinculadas, precisamente, con las gestiones que sus padres habían encarado para dar con su paradero. Luego de relatar el reencuentro familiar en la comisaría a la que había sido llevada después de su salida del Vesubio y con anterioridad a su traslado al Penal de Devoto, se dispuso a leerme los documentos:

Y estas eran de mis compañeras, eh, dice...: “Al señor $\mathrm{S}$. y su señora esposa. El motivo de esta carta es para agradecerle todas
las atenciones...” - porque los primeros que fueron, fueron mis padres- “...que tanto usted como su familia han tenido para
todo el grupo, nosotros hemos vivido momentos muy duros, los vivimos aún, pero actitudes, afectos, cariños como los que
nos han hecho llegar a través de Silvia, nos hacen sentir un poquito parte de su familia, nos llenan de una gran ternura y de
un gran afecto hacia usted y su familia. Nos han hecho sentir menos solos. Nuestros corazones y nuestros pensamientos no
dejarán nunca de agradecerles todas las atenciones y las molestias que se tomaron con nosotros. Muchas gracias por ser tan
buenos y tan padres”... Eso es lo que tenían mis padres, que..., bueno, mi mamá era mucho más, este... [sonríe] mucho más
humanista, mi papá era más... si bien era socialista, pero era un gorila que mamma mía, y... y yo te había contado que él decía
que mejor nos maten a todos, ipero eran muy solidarios! Yo la solidaridad la aprendí de ellos.

En particular, las referencias a esa búsqueda y a los tiempos posteriores a su desaparición, parecerían resignificar un vínculo que, hasta entonces, había sido evocado desde sus profundas tensiones. Al describir el reencuentro con su familia, lo hacía de la siguiente manera:

Ellos me encontraron el 13 de octubre [de 1978]. Eh... yo tenía como una corazonada, ¿viste? (...) Y cuando el Cabo Pino me busca, me dice: "Arreglate, arreglate que vas para adelante". [Con un tono diferente, como de alivio, como volviendo a ver a sus padres] Yo dije: “¿qué, me vinieron a ver?”, y este, bueno, “peinate, ponete bien, arreglate”. Y ahí estaba..., estaba mi papá, mi mamá y mi hermana, que los vi a todos... Siempre fueron gordos, estaban todos flacos, chupados. Mi mamá y mi papá canosos... en el poco tiempo ese que yo no estuve...

Casi 8 meses después de su legalización, Silvia fue liberada junto a otros compañeros. A partir de aquí, se iniciaría para ella un arduo proceso de silencio y aislamiento que se solapó con un marcado retraimiento sobre su vida familiar y sobre los ámbitos privados de la vida cotidiana. Durante aquellos años, uno de los pocos vínculos que retomó fue el de una vieja amiga y compañera de militancia con quien había compartido, también, el período de secuestro y posterior encarcelamiento - con ella, también, comparten en la actualidad la militancia en derechos humanos-. Los propios pesares por lo vivido, junto con apremios familiares - 
principalmente vinculados con la enfermedad y posterior muerte de A., el menor de sus cuatro hijos- y económicos, la llevaron a retraerse sobre y refugiarse en ese mundo más íntimo:

Estuve mucho tiempo con la enfermedad de A. y la debacle económica de mi familia, estuve como... muy metida para adentro para sostener a mi familia, entonces había como... anteojeras. Cuando falleció A. en octubre del 98 y en mayo del 2000 me separo, empiezo... a mirar hacia afuera. Y ahí me busca M. [en relación al sobrino de una compañera de cautiverio cuyo bebé había sido apropiado, y que en su propio proceso de búsqueda del ser querido la había contactado para conocer su testimonio] (Silvia, comunicación personal, 8 de marzo de 2012).

En efecto, no sería sino muchos años más tarde cuando, interpelada desde la relevancia de su propio relato, comenzaría a abrirse a nuevos espacios y plantarse en la escena pública.

La historia de Laura trae, también, la idea del aislamiento y la negación en conjunción con un repliegue sobre el espacio privado que habría ido pautando formas posibles de recomposición subjetiva. ${ }^{25}$ En nuestras conversaciones, Laura repasó un conjunto de desvinculaciones que sucedieron a su liberación y que pueden pensarse como parte constitutiva de rupturas mayores: la de la pareja, la de su militancia y el consecuente alejamiento de sus compañeros y amigos - al menos, en los primeros tiempos-. En su relato, lo vivido en el campo la llevaba a "relativizar toda las creencias que uno tenía"y replantearse, con ello, su propia cotidianeidad y el conjunto de entramados afectivos que hasta entonces la atravesaban. Por ese entonces, Laura se separó de su pareja y se reencontró con un viejo amor, ajeno a ese mundo vinculado con la política y con quien compartiría parte de su exilio; al mismo tiempo, en los momentos inmediatamente anteriores a su partida al exilio, dejó de frecuentar los espacios y relaciones vinculados con la militancia. El relato mismo de esas desvinculaciones parece hacer serie con una cadena de escisiones que comienzan a suscitarse entre ese mundo pleno y casi englobante de la militancia y su fragmentación posterior:

Yo sentía que tenía que irme pero avisar. Yo no podía... borrarme y desaparecer. (...) Y, bueno, y ahí sentí que, bueno, puse fin... También, lo vi a mi ex y le dije que me iba a hacer... O sea, yo tenía que cerrar todas las... puertas. No podía dejar nada sin... Bueno, a parte, la locura. A parte, yo creo que también algo que me pasó es que creía que con eso yo ya pagaba todo, ¿entendés? Como que si algo yo tenía que pagar por haber militado, ya estaba. Entonces como que eso me daba como una cosa de impunidad. De ahora en más yo era..., este... ¡ya estaba!

Las referencias mismas a su exilio y particularmente a su llegada a Israel, donde se encontraría con su novio, dan cuenta también de estas escisiones y decisiones:

Decidimos irnos a Israel. Había un grupo muy grande que se iba a ir a Israel. Chicos del Pellegrini y del Buenos Aires. Y, entonces, él me dice: "Encontrémonos en Israel”. Entonces, yo de Nueva York me voy a Israel, donde también había... parientes de mi papá. Y estoy unos días en casa de ellos y, finalmente, me encuentro con H., que era este pibe, mi novio. Y cuando lo voy a buscar para... (se supone que de ahí nos íbamos a ir a un Kibutz, para estar 6 meses en un Kibutz), y cuando voy era... ¡conocía a todos! Era un avión entero de gente que se rajaba, de compañeros de militancia... Y, ahí, bueno, ahí, decidimos que..., él no era de la agrupación, entonces, bueno... Y yo tampoco quería tener mucho contacto con... mis ex compañeros [sonríe]. Finalmente, decidimos irnos a otro Kibutz, no al que iban todos. Y, bueno, y ahí estuvimos... 7 meses en total.

Sin embargo, a diferencia de otros casos y aún en un contexto de terror y desarticulación generalizada de los espacios colectivos, aparece en estos fragmentos algo del orden de la propia decisión que sutura tanto en la voluntad de "cerrar" una parte de ese pasado como en la elección concreta del lugar de residencia en el exilio. Esas "decisiones" se solaparán también -y fundamentalmente luego del regreso al país, en plena dictaduracon otras formas de repliegue sobre el ámbito privado de interrelación. En efecto, el exilio parecía iniciar una nueva etapa, alejada de sus vínculos hasta entonces más próximos y recluida sobre el espacio familiar y sus estudios. A partir de entonces, lo vivido permanecería en una zona silenciada, como negada, ocluida:

Era muy peligroso volver en ese entonces... Este, y yo vuelvo, y me pongo a estudiar. Me meto en la facultad y empiezo a hacer como... ¡ borrón y cuenta nueva! (...) Y, bueno, y yo vuelvo a vivir con mi vieja. Y, claro, yo supongo, tenía esta sensación de que ya... Bueno, primero hago... “iya está!”. O sea, todos los que habían sido mis amigos estaban yéndose, o ya se habían ido, o habían caído, o... Con lo cual, yo empiezo como una vida... nueva. Me anoto en la facultad, me pongo a estudiar, este... 
Y, ahí (esto es parte de esto), bueno, iy nunca más hablo de lo que pasó! Porque... como que una forma de sostenerlo era... ¡olvidarte que pasó, digamos!

De aquí en más, y anudado a ese "borrón y cuenta nueva", el estudio ocuparía un lugar central en su vida, siendo ámbito de nuevos entramados, de nuevos encuentros y afectos. En este sentido, implicó para ella una "vida nueva": desvinculada de muchos de sus compañeros y de su propia historia y en un profundo silencio sobre lo vivido - como en un intento de olvido ${ }^{26}$, durante los años subsiguientes permaneció en espacios ajenos y distantes de esas formas de acción y relación. Presa de un "terror de base”, en ese marco comenzó sus estudios de Arquitectura y es así que señalaba:

Y en la facultad, a ver, en la facultad teníamos..., también, me tragué del 77 al 82. O sea, yo estudio todos los años de la dictadura, pero bueno, dentro de la facultad, también, con un grupo... Había como algunas movidas paralelas, de... Había una cosa que se llamaba "La Escuelita", donde los profesores que no estaban en la facultad, porque estaban... echados, o qué sé yo, daban clases. Entonces, yo empecé a ir a estos lugares. Por otro lado, con un grupo de compañeros, también, armamos una revista... con, que era una forma, ¿¿no?, como eran pequeñas expresiones [sonríe], este... Y esas cosas. Pero a mí siempre... tenía como un terror de base, yo, en estas cosas. Me daba miedo participar en esto. Participaba hasta ahí... Había quedado muy... golpeada. Pero ni siquiera..., ¡mis compañeros de facultad no sabían mi historia! No se las... contaba tampoco.

El terror y el silencio iban cercenando su disposición a la acción/participación. ${ }^{27}$ Una vez iniciada la democracia murió su madre, lo que la sumió en una tristeza muy profunda y un marcado repliegue sobre el espacio íntimo que le impidió pensar -señala- en la posibilidad de la denuncia pública de lo vivido:

Muchos años después mi vieja se enfermó, todo esto... hizo su mella. Una leucemia. Y falleció en el 83. En diciembre del '83. [Sonríe] Justo cuando asumió Alfonsín, se murió mi vieja. A la semana. Y, con lo cual, eso también... Por ahí ese era el momento de hablar, que era... lo de la denuncia de la CONADEP, y hubiera sido el momento de contarlo todo. Y yo estaba..., nada, había muerto mi vieja una semana antes y yo estaba destruida. Y la verdad que no tuve energía para, en ese momento, hacer ninguna denuncia. Y ahí pasó el tiempo y, viste, y ya después uno se acostumbra a no hablar de algunas cosas [sonríe] (Laura, comunicación personal, 19 de julio de 2011).

Así prosiguieron los años, se casó con un compañero de facultad y tuvo a sus tres hijos. Con el tiempo, retomó el vínculo con muchos de sus compañeros y fue inscribiendo, también, su propia historia y su relato en la escena pública.

Con un embarazo avanzado, Susana había vuelto a vivir en su casa materna. Como había mencionado, ya en los primeros tiempos posteriores a su liberación, comenzaba a sentirse la soledad por los compañeros ausentes -algunos desaparecidos, otros exiliados- y, fundamentalmente, la de su compañero. En ese marco, se fue recluyendo sobre sus vínculos más cercanos y la crianza de su pequeño. En esos años, también, terminó sus estudios de magisterio, donde pudo recomponer poco a poco nuevos espacios de pertenencia:

Yo empecé como a separarme un poco de lo que era J. [su hijo], no de lo que..., un poco más a vivir más mi vida, cuando empecé el profesorado devuelta en el Mariano Acosta, ique tuve amigos, ahí! Empecé a tener amigas y amigos, a estudiar, digamos. Pero igual, no... [Con un tono bajo, triste] Era muy, muy difícil... (...) Los únicos que habían quedado, así, compañeros de militancia queridos, también se fueron. Así que, bueno, por eso fue importante cuando empecé a armar todos esos lazos en el Mariano Acosta.

[Con un tono más animado] Y, bueno, así que empecé a estudiar y a estar con ellos. Lo llevaba a J. P., también, a la cantina porque no tenía dónde dejarlo. Así que lo dejaba ahí en el bar del Mariano Acosta que me lo cuidaban, y me iba a estudiar. Él tenía 2 años. Así durante toda la carrera.

Llevar adelante sus estudios no fue tarea sencilla. No sólo por la crianza de su hijo pequeño sino también porque debió enfrentar otras dificultades y prejuicios. Sin poder hablar abiertamente sobre la suerte de su compañero, Susana se presentaba al mundo como madre soltera:

Y, bueno, y era difícil. Porque él llevaba mi apellido y había como mucho, todavía en esa época, mucho prejuicio, viste. (...) Por ejemplo, la ley esta de los milicos que las madres solteras no podían ser maestras. Entonces, yo hice toda la carrera y en uno de los exámenes, una mina que era una guacha, me dijo "Usted nunca va a ser maestra”. ¿Entendés? Porque yo era madre soltera (Susana, comunicación personal, 29 de noviembre de 2011). 
Aun así, terminó sus estudios. Y fue ese sostén afectivo -el de los nuevos vínculos y de su propia familiael que le permitió comenzar a reponerse, al menos parcialmente. Sin embargo, debieron pasar muchos años hasta lograr una escucha y un entendimiento que sólo los pares podrían brindarle.

$\mathrm{Al}$ igual que Susana, Nieves cursó su embarazo en cautiverio. Primero, detenida de manera clandestina en el Vesubio y luego en el penal de Devoto donde -como dijimos- nació su hija, y donde se produjeron los primeros reencuentros familiares. Al salir en libertad, el mundo de interacción se había reducido drásticamente, al tiempo que la propia vida ya no era la misma: no sólo había estado desaparecida sino que, ahora, era mamá. Sin poder volver a dar clases en la escuela pública ni regresar a la facultad -actividades que la ocupaban con anterioridad a su secuestro-, y viviendo en su casa materna, Nieves recuerda estos tiempos con pesar, como parte de "un antes y un después":

Todo lindo cuando nos liberaron, todo hermoso, bárbaro, llegaste a casa, estábamos todos pero..., o sea, tu vida se había partido: yo ya tenía un sumario en la escuela, no podía volver a la escuela, no podía volver a la facultad porque había perdido la regularidad y tenía que hacer todo un trámite para poder volver. Pero además no estaba bien anímicamente, estaba angustiada, tenía una hija, no tenía trabajo... O sea, todo hermoso al principio pero después la realidad de la cotidianeidad es que tu vida fue un antes y un después.

Con el tiempo, Nieves pudo ir rearmando la vida, repartida entre el cuidado de su hija, una nueva inserción laboral en el jardín de infantes que dirigía su mamá y el reanudamiento de los estudios universitarios. Fue allí, en efecto, que logró volver a armarse de un grupo de pertenencia:

$\mathrm{Al}$ año siguiente, sí, empecé a trabajar en el jardín de mi mamá a la tarde y a cursar en la facultad. Y eso ya como que me fue dando un respiro, un volver a la rutina. Mi mamá me cuidaba a la nena cuando yo iba a trabajar o cuando iba a la facultad y, bueno, me fui haciendo de algún grupo de pares en la facultad, nuevos grupos porque los que habían arrancado conmigo ya estaban más adelante... Y bueno, me aboqué, o sea, mi meta era terminar.

Hasta entonces, sólo había mantenido el vínculo con otras dos excompañeras que habían sido madres, junto con ella, en Devoto:

Eran también compañeras del partido, pero yo más las conocí ahí en Devoto, y me veía con ellas los fines de semana. No tenía muchos grupos de amigos, porque mis amigos, la mayoría no estaban o estaban desaparecidos o no los podía ver o no era conveniente que los vea o qué sé yo qué... Salvo con estas dos compañeras de Devoto que me veía así, a veces los fines de semana... Y con Virginia, (...) amiga mía de la vida.

Ya en democracia, las alternativas se fueron ampliando y logró poco a poco retomar algo de aquello que había quedado trunco:

Y ya cuando llegó..., para más o menos la época de Alfonsín, yo ya pude reingresar a la escuela y empecé de nuevo a trabajar en el escuela pública, entonces trabajaba un turno en el jardín, un tuno en la escuela pública y después también, terminando de cursar las materias (Nieves, comunicación personal, 3 de mayo de 2012).

Durante este tiempo, y por largos años, Nieves permaneció en silencio sobre lo vivido. Al igual que en otros casos, sólo el tiempo y los espacios de contención adecuados irían propiciando reencuentros, animando a romper el silencio y a nuevas formas de participación en la escena pública.

Como vemos a partir de estas historias, al proceso de ruptura anudado a la (propia) desaparición se contrapuso un repliegue y un apoyo sobre otros espacios de interacción -principalmente, la familia de origen y/o los estudios- hasta entonces eclipsados fuertemente por la actividad política. Sin embargo, lejos de conformar meramente la contracara dada o necesaria de esas desarticulaciones de los espacios de pertenencia, el proceso de repliegue sobre estos nuevos (o viejos) ámbitos fue operando, fuertemente, como resguardo en tanto que propiciaron el sostén necesario para transcurrir los tiempos inmediatamente posteriores a la liberación e iniciar, con ello, el arduo, complejo y extenso proceso de re-aparición y de recomposición de la propia subjetividad avasallada en y por la experiencia límite. Estas recomposiciones, aunque lábiles, fueron el puntapié primario para nuevos recorridos que se vincularán ya no, o no tan solo, con la trama de lo privado 
sino con formas más o menos visibles y/o sostenidas - de acuerdo a cada caso- de reinscripción en el espacio público.

\section{4) Consideraciones finales: Mundos (DES)APARECIDOS, ALGUNAS (RE)CONSTRUCCIONES POSIBLES}

En este artículo me aboqué al análisis de los espacios de acción e interacción que se vieron sacudidos y re-configurados por la experiencia de la (propia) desaparición. En un escenario de desarticulación social producida por la desaparición forzada como tecnología de poder, advertimos movimientos de ruptura y desarticulación de los espacios de pertenencia vinculados con el hacer político que se fueron solapando, no obstante, con nuevas tramas de interacción, propiciadoras de las primeras formas de cobijo y resguardo. Dije, ante todo, que si la militancia política había abierto a nuevos horizontes de sentido y formas de construcción del lazo y configuración de la vida cotidiana, su cercenamiento y el ultraje mayor que significó la (propia) desaparición fueron devastando al/los sujeto/s; el mundo de lo conocido se dislocaba y, con él, los espacios de interrelación y acción colectiva se vieron trastocados.

En este marco, y al menos en los primeros tiempos, la soledad fue produciendo su mella: gran parte de los compañeros no estaban ya, muchos habían desaparecido, otros se habían exiliado, otros -inclusocuestionaban el por qué de la liberación. Estas formas de aislamiento, que daban cuenta de la ausencia de pares y/o de terceros que devolviesen la mirada y un entendimiento sobre lo vivido, fueron reforzando y profundizando los efectos de la crueldad. Sin embargo, frente a estas rupturas del mundo colectivo y de la vida "pública", el repliegue sobre el espacio íntimo -aquel que, como dijimos, se había visto opacado y/ o desdibujado por el hacer político- fue propiciando formas incipientes - pero necesarias- de cobijo y de cuidado que, incluso desde el silencio sobre lo vivido, brindaron contención y resguardo. Desde allí, y a lo largo de los años, algunos más pronto, y otros en un lapso mayor de tiempo, los sobrevivientes -sino todos, al menos sí los que componen este estudio- fueron retomando viejas y nuevas actividades, recuperando vínculos, construyendo otros.

De manera diversa, la desarticulación producida por la (propia) desaparición y posterior liberación -como pura ruptura de lo que conformaba hasta entonces la vida- se fue rearmando, entonces, en y con nuevas y variadas formas de reconstrucción de lazos y entramados intersubjetivos. Y, así, los sujetos fueron (y van, aún hoy) (sobre)viviendo. En este sentido, este movimiento de reinscripción en nuevos (o viejos) entramados y espacios sugieren que, lejos de remitir a la pura ruptura y/o a la pérdida de un mundo propio -como escisión plena y duradera entre un antes y un después absolutos-, la vida con posterioridad a la liberación se fue reconstruyendo sobre la base de múltiples reconfiguraciones y re-anudamientos que fueron viabilizando de acuerdo al contexto y a la dinámica de cada caso formas singulares de elaboración y cierto recupero de aquello propio de lo sido: los vínculos familiares, la reanudación de los estudios y/o de viejos amores van dando cuenta, en efecto, de una búsqueda en torno de ese tiempo (otro) anterior a la (propia) desaparición, aunque escindido de la acción política y los espacios de interrelación anudados a ella. Con ello, no es tan sólo el pesar por lo perdido lo que emerge en los relatos sino también sus múltiples re-construcciones posibles. Ruptura y reanudamiento o re-construcción como movimientos conjuntos y constitutivos -en absoluto excluyentes o antagónicos- de la (sobre)vida.

\section{ReFERENCIAS}

Actis, M., Aldini, C., Gardella, L., Lewin, M. y Tokar, E. (2001). Ese Infierno. Conversaciones de cinco mujeres sobrevivientes de la ESMA. Buenos Aires: Editorial Sudamericana.

Agamben, G. (2000). Lo que queda de Auschwitz. El archivo y el testigo. Homo Sacer III. Valencia: Pre-textos.

Arfuch, L. (2010). El espacio biográfico. Dilemas de la subjetividad contemporánea. Buenos Aires: FCE. 
Julieta Lampasona. “(Des)AParición y después. ENTre El ARrasamiento y La (Re)Construcción DE LOS E...

Asociación de Ex Detenidos Desaparecidos (AEDD) (s/f). ¿Por qué sobrevivimos? Recuperado de: http://www.exde saparecidos.org.ar/aedd/sobrevivimos.php.

Bettelheim, B. (1983). Sobrevivir. El holocausto una generación después. Barcelona: Ed. Crítica, Grijalbo.

Calveiro, P. (1998). Poder y desaparición: los campos de concentración en la Argentina. Buenos Aires: Colihue.

Carnovale, V., Lorenz, F. y Pittaluga, R. (2006). Memoria y política en la situación de entrevista. En torno a la constitución de un archivo oral sobre el Terrorismo de Estado en la Argentina. En Historia, memoria y fuentes orales. Buenos Aires: CeDInCI Editores.

Feierstein, D. (2007). El genocidio como práctica social. Entre el nazismo y la experiencia argentina. Buenos Aires: Fondo de Cultura Económica.

González Tizón, R. (2018). Militancia humanitaria y testimonio. Los sobrevivientes de "El Vesubio" y la denuncia de los crimenes de la última dictadura (1976-2016) (Tesis Doctoral inédita). Instituto de Altos Estudios Sociales, Universidad Nacional de General San Martín, Buenos Aires.

Izaguirre, I. (2009). El mapa social del genocidio. En I. Izaguirre (Comp.), Lucha de clases, guerra civily genocidio en la Argentina (1973-1983) (pp. 73-117). Buenos Aires: Eudeba.

Jelin, E. (2002). Los trabajos de la memoria. Buenos Aires: Siglo Veintiuno.

Jelin, E. (2006). La narrativa personal de lo invivible. En V. Carnovale et al., Historia, memoria y fuentes orales (pp. 63-79). Buenos Aires: CeDInCI.

Kaufman, S. (1998). Sobre violencia social, trauma y memoria. En Seminario Memoria Colectiva y Represión, Montevideo, 16-17 de noviembre.

Kordon, D., Edelman, L., Lagos, D., Nicoletti, E., Bozzolo, R., Siaky, D., ..., Kersner, D. (1986). Efectos psicológicos de la represión politica. Buenos Aires: Sudamericana - Planeta.

LaCapra, D. (2005). Escribir la historia, escribir el trauma. Buenos Aires: Nueva Visión.

Laub, D. (1992). Bearing witness or the vicissitudes of listening. En S. Felman y D. Laub, Testimony: Crises of witnessing in literature, psychoanalysis, and history. New York: Routledge.

Levi, P. (2005). Trilogía de Auschwitz. Barcelona: El Aleph.

Longoni, A. (2007a). Traiciones. La figura del traidor en los relatos acerca de los sobrevivientes de la represión. Buenos Aires: Editorial Norma.

Longoni, A. (2007b). Los sobrevivientes. Voces para un debate necesario. Revista Puentes, 7(21).

Maneiro, M. (2005). Como el árbol talado. Memorias del genocidio en La Plata, Berisso y Ensenada. Buenos Aires: Ediciones al Margen.

Messina, L. (2012). Reflexiones en torno a la práctica testimonial sobre la experiencia concentracionaria en Argentina. Sociedad y Economia, 23, 37-58.

Oberti, A. (2009). Lo que queda de la violencia política. A propósito de archivos y testimonios. Revista Temáticas, $17(33 / 34), 126-148$.

Oberti, A. (2015). Las revolucionarias. Militancia, vida cotidiana y afectividad en los setenta. Buenos Aires: Edhasa.

Pollak, M. (2006). Memoria, Olvido, Silencio. La producción social de identidades frente a situaciones límite. La Plata: Ediciones al Margen.

Puget, J. (1991). Violencia social y psicoanálisis. De lo ajeno estructurante a lo ajeno-ajenizante. En J. Puget y R. Kaës (Eds.), Violencia de Estado y psicoanálisis (pp. 25-56). Buenos Aires: Centro Editor de América Latina.

Puget, J. y Kaës, R. (Eds.) (1991). Violencia de Estado y psicoanálisis. Buenos Aires: Centro Editor de América Latina.

Rama, C. (2015). Sobreviviendo: Experiencias en el marco del proceso de aparición de sobrevivientes de los centros clandestinos de detención de la última dictadura militar (Tesis de licenciatura inédita). Facultad de Filosofía y Letras, Universidad de Buenos Aires, Buenos Aires.

Ricoeur, P. (2004). La memoria, la historia, el olvido. Buenos Aires: Fondo de Cultura Económica.

Rousseaux, F. (2009). Tomar la palabra: testimonios y testigos en el marco de los procesos contra el terrorismo de Estado en la Argentina. En Acompañamiento a Testigos y Querellantes en el Marco de los Juicios contra el 
Terrorismo de Estado. Estrategias de Intervención. (Segunda Parte). Boletín Oficial de la República Argentina, Año CXVII, Número 31.712. Buenos Aires.

Rousseaux, F. y Duhalde, E. L. (2015). El ex detenido-desaparecido como testigo de los juicios por crimenes de lesa humanidad. Buenos Aires: Fundación Eduardo Luis Duhalde.

Sautú, R. (1999). Elmétodo Biográfico. La reconstrucción de la memoria de la sociedad a partir del testimonio de los actores. Buenos Aires: Ed. de Belgrano, Universidad de Belgrano.

Schmucler, H. (1980). Testimonio de los Sobrevivientes. Revista Controversia, 9/10, 4-5.

Semprún, J. ([1995] 2004). La escritura o la vida. Buenos Aires: Tusquets Editores.

Tolentino, M. (2016).“Porque sabemos la verdad, tenemos memoria, exigimos justicia”: la trayectoria de la Asociación de Ex Detenidos-Desaparecidos (1984-2014). En IX Seminario Internacional Politicas de la Memoria. Buenos Aires, 3-5 de noviembre.

Ulloa, F. (24 de diciembre de 1998). Pensar el dispositivo de la crueldad. "La encerrona trágica" en las situaciones de tortura y exclusión social. Página/12. Recuperado de http://www.pagina12.com.ar/1998/98-12/98-12-24/psi co01.htm

Vasilachis, I. (2006). Estrategias de Investigación cualitativa. Barcelona: Gedisa.

Vega Martínez, M. (1997). La desaparición: un proceso mucho más complejo que la muerte de un individuo. En I. Antognazzi y R. Ferrer (Comps.), Argentina las raíces históricas del presente (pp. 183-194). Rosario: Universidad Nacional de Rosario.

Waisbrot, D., Wikinski, M., Rolfo, C., Slucki, D. y Toporosi, S. (Comps.) (2003). Clínica Psicoanalitica ante las catástrofes sociales. La experiencia argentina. Buenos Aires: Paidós.

\section{Notas}

1 Se incluye el despliegue del Operativo Independencia en la provincia de Tucumán (iniciado en febrero de 1975) y las acciones clandestinas de la Alianza Anticomunista Argentina.

2 Las nociones de liberados, ex detenidos-desaparecidos y sobrevivientes constituyen diferentes categorías nativas que buscan nominar la experiencia límite de la (propia) desaparición. Configurada como una modulación específica de la tecnología de la desaparición forzada de personas, esta experiencia supuso en su despliegue la articulación de las situaciones de selección-persecución - secuestro - tortura - cautiverio - liberación de los CCD produciendo, con este último movimiento, la emergencia de la figura de los sobrevivientes. Cabe señalar, no obstante, que estos sujetos no conforman a priori un colectivo homogéneo pues, al tiempo que registran múltiples trayectorias de vida, cada uno de ellos fue desplegando también diferentes modos de elaboración de la violencia vivida y, particularmente, de inserción y/o vinculación con el movimiento de derechos humanos y/o las instancias de denuncia. En efecto, mientras que algunos participaron temprana y activamente de los organismos -conformando, incluso, asociaciones de sobrevivientes-, otros se mantuvieron alejados -y se mantienen, en algunos casos- de esas formas de militancia y/o participación en el espacio público. Atenta a esta diversidad, me referiré al conjunto con la categoría de sobrevivientes pues considero, por un lado, que permite englobar esas diferentes trayectorias y posiciones y dar cuenta, al mismo tiempo, de una experiencia común: la de haber permanecido desaparecidos y, no obstante, haber sobrevivido. Pero también, y sobre todo, la categoría trae consigo una apertura temporal que permite pensar más allá de un tiempo y una espacialidad cerrados en sí mismos: no se trata tan sólo de un "ex", sino de un sujeto que vive y pervive, en el presente, pese a todo. Y que trae consigo, en esa persistencia, un "plus" de vida y una potencia.

3 La experiencia de la (propia) desaparición y posterior sobrevida promovió, en muchos casos, formas de entrampamiento subjetivo cuya vigencia se sostuvo más allá de los límites espacio-temporales del CCD y se tornó asible en el acecho acuciante de lo vivido, en profundos pesares y miedos, entre otros aspectos.

4 Como señalan diversos autores (Calveiro, 1998; Vega Martínez, 1997; Maneiro, 2005; Feierstein, 2007; Izaguirre, 2009; entre otros), los procesos represivos - asentados particularmente en la desaparición forzada de personas como la principal tecnología de poder-, promovieron profundas rupturas del tejido social y la desarticulación de las solidaridades y territorialidades del campo popular. En efecto, el despliegue del terror fue generando procesos de aislamiento e inmovilidad frente al poder represivo, resquebrajando con ello los espacios de participación colectiva y pertenencia, y desamparando y aislando al/los sujeto/s (Puget, 1991). Lejos de acotarse en el tiempo, los efectos de dichas rupturas se sostuvieron en el largo plazo. Estos procesos impactaron fuertemente en las historias de vida que componen este estudio, 
en las que la militancia política aparece como un eje de referencia sustantiva que, evocado desde una marcada fortaleza afectiva y la intensidad de los vínculos e identidades que allí se fueron forjando, puso en tensión otros entramados de relación y/o cosmovisiones del mundo hasta entonces construidos. Conviene señalar, no obstante, que los espacios de militancia han sido escenario de tensiones y diferencias (Oberti, 2015); ahora, en función de los objetivos de la investigación -vinculados con el análisis de los modos de inscripción biográfica de la experiencia límite- se reparará aquí en las remisiones a la fortaleza de esos vínculos con el objeto de avanzar sobre la pesadez y/o desazón que, desde la evocación, parecen anudarse a sus posteriores rupturas.

5 La investigación en que la que se enmarca este trabajo recupera particularmente los desarrollos sobre los lager nazis (Bettelheim, 1983; Agamben, 2000; Semprún, 2004; Levi, 2005) y, en particular, sobre los CCD argentinos en su cualidad deshumanizante y cruel (Calveiro, 1998; Ulloa, 1998; Waisbrot, Wikinski, Rolfo, Slucki y Toporosi, 2003; entre otros). Asimismo, resultaron nodales también los abordajes que han hecho foco en la dimensión de lo traumático, los procesos de elaboración/rememoración y el testimonio como instancia de reconstrucción subjetiva e identitaria (Laub, 1992; Ricoeur, 2004; LaCapra, 2005; Pollak, 2006; Jelin, 2002 y 2006; Carnovale, Lorenz y Pittaluga, 2006; Oberti, 2009; Rousseaux, 2009, entre otros). En relación con la figura de los sobrevivientes conviene señalar que, si bien es aún un campo en desarrollo, existen antecedentes sustantivos que permiten complejizar tanto el lugar social de estas voces, los anclajes sociopolíticos de los procesos de estigmatización que las rodean y las pretensiones terroríficas de ese poder concentracionario que, al tiempo que desaparecía, también liberaba (Schmucler, 1980; Calveiro, 1998; Longoni, 2007a y 2007b; AEDD, s.f.). En este marco, los abordajes más recientes fueron desplazando sus miradas progresivamente hacia la singularidad de esta experiencia, atendiendo al problema del testimonio y su cruce con la figura del testigo, como así también a sus propias tensiones, dolores y vivencias como sujetos políticos y víctimas-testigos del dispositivo concentracionario, durante y después de la experiencia límite (Rousseaux y Duhalde, 2015; Rama, 2015; Tolentino, 2016; González Tizón, 2018).

6 Si la experiencia del CCD había configurado una situación de crueldad extrema (Ulloa, 1998), los procesos de desvinculación posteriores a la liberación -junto con las formas de sospecha y marginación que afectaron tempranamente a los sobrevivientes (Longoni, 2007a) sostuvieron, e incluso reforzaron, sus efectos devastadores.

7 No se hará foco aquí en los espacios laborales dado que, aunque fuera mencionado, no fue uno de los principales nudos de referencia. Para un abordaje sobre esas reinserciones ver Rama (2015).

8 El abordaje metodológico de nuestra investigación se estructuró sobre un diseño cualitativo centrado en el abordaje biográfico, permitiendo analizar las articulaciones entre la singularidad y los procesos sociales de conjunto (Sautú, 1999; Vasilachis, 2006; Arfuch, 2010). Nuestro trabajo de campo consistió en la búsqueda de fuentes secundarias principalmente, testimonios orales del Archivo Oral de Memoria Abierta y libros autobiográficos de sobrevivientes de diferentes CCD- y la construcción de fuentes primarias a partir de entrevistas en profundidad a hombres y mujeres que, por su carácter biográfico, conformaron historias de vida. Las 15 historias de vida que componen nuestro corpus fueron relevadas entre los años 2011 y 2015 -años signados por una marcada relevancia pública de la temática vinculada con la(s) memoria(s) del pasado dictatorial y que impactaron, incluso, en los modos de rememorar y revisitar las propias historias- y estuvieron distribuidas de manera homogénea entre hombres y mujeres, cuyas experiencias de cautiverio tuvieron lugar en diferentes CCD del país - principalmente, la Ciudad de Buenos Aires y el Gran Buenos Aires-. Al mismo tiempo, la selección de los casos procuró reflejar la marcada heterogeneidad que, en términos de los momentos de producción del testimonio y de la participación (o no) en el espacio público, es observable al interior del "colectivo" de sobrevivientes y que nos permite aproximar a los diversos modos de vincular-se, decir-se y hacer en relación con lo vivido; con ello, se incluyeron trayectorias con una temprana y activa participación y otras más alejadas de las formas de activismo en derechos humanos o con una aproximación más reciente, y parte de esa diversidad se refleja en los casos seleccionados para este trabajo con el objetivo de encontrar sus nudos comunes.

9 Estos últimos, no obstante, serán marcadamente diferentes a aquellos que, posteriores a la situación de violencia, emergieron como efectos de los procesos de crueldad.

10 La referencia a los nombres de los entrevistados varía en términos de la voluntad de mayor o menor anonimato de cada entrevistado/a. En los casos en los que dieron su acuerdo, se hará referencia al nombre de pila real con exclusión del apellido. En los casos en que prefirieron un mayor nivel de anonimato, se hará referencia a un nombre ficticio -tal es el caso de "Julián"-. Militante del peronismo de izquierda, Miriam fue secuestrada en mayo de 1977 y recluida en diferentes CCD de la Capital Federal, hasta enero de 1979. Exiliada en Estados Unidos -donde inició su tarea de denuncia-, regresó a la Argentina una vez restaurada la democracia e inició su intenso recorrido testimonial por múltiples espacios y soportes -incluidos la CONADEP y el Juicio a las Juntas-, hasta el presente. Realizamos nuestros encuentros entre mayo y septiembre de 2011.

11 Alejados de sus espacios de militancia dentro del peronismo de izquierda, Susana y O. [su compañero] habían sido secuestrados en junio de 1977 mientras cursaban los primeros meses del embarazo de quien sería su primer y único hijo, y permanecieron cautivos en el CCD “El Vesubio”. Un mes después del secuestro O. fue "trasladado" y permaneció desaparecido hasta que en 2009 sus restos fueron identificados por el Equipo Argentino de Antropología Forense 
(EAAF). Susana permaneció detenida hasta mediados de septiembre y dio a su luz a su pequeño en noviembre de ese año, ya en libertad. Actualmente es una reconocida militante del campo de los derechos humanos, ha brindado testimonio en múltiples instancias y dirige una escuela para personas en situación de calle. Realizamos nuestros encuentros entre noviembre de 2011 y febrero de 2012.

12 Militante de Vanguardia Comunista, Nieves fue secuestrada en julio de 1978 y detenida en el CCD "El Vesubio" hasta mediados de septiembre, cuando fue legalizada para ser trasladada finalmente al Penal de Devoto, donde dio a luz a su primera hija. En mayo de 1979 obtuvo la libertad. Luego de largos años de una escasa participación en el campo de los derechos humanos, actualmente tiene una activa militancia.

13 El significante caída es utilizado en el universo de sentido vinculado con la desaparición forzada para designar el/los secuestro/s.

14 Por su parte, conviene señalar que esas rupturas anudadas al despliegue del terror se solaparon también con diversas formas de sospecha y cuestionamientos en torno del porqué de la liberación. Ver: Longoni (2007).

15 Cabe aclarar que, según entiendo, liberación y (construcción social y subjetiva de) libertad suponen procesos disímiles. Por liberación entiendo el proceso por el cual el sujeto dejaba de estar recluido en los espacios de desaparición como detenido-desaparecido-, a partir de modalidades diferenciales, sea bajo el régimen de "libertad vigilada", como legalización y puesta a disposición del Poder Ejecutivo Nacional -esto es, en cárceles del Servicio Penitenciario-, y/ o la liberación seguida de insilio/exilio. La noción de libertad, por su parte, remitiría a procesos de recomposición y elaboración, subjetivos y sociales, y que se vinculan con las complejidades del re-aparecer y su devenir en el largo plazo.

16 Con la letra $E$ me referiré a las intervenciones propias en el rol de entrevistadora, mientras que el nombre del entrevistado se referirá a través de su inicial.

17 De profesión docente, a comienzos de los años 70 comenzó su actividad político-gremial y su militancia en la Juventud Peronista. Allí conoció a quien sería el padre de sus dos hijos, quien en febrero de 1977 -luego del primer secuestro de Delia- fue secuestrado y continúa desaparecido. En enero de 1977, cursando su segundo embarazo, Delia fue secuestrada y permaneció detenida por algunos días en lo que posteriormente identificaría como el CCD "El Sheraton", en la comisaría de Villa Insuperable. Esa detención produjo secuelas graves en su embarazo y su niña nació con una parálisis neurológica irreversible que la dejaría vivir tan sólo 10 años. En agosto de ese año, habiendo sido detenido ya su compañero -quien continúa desaparecido- Delia fue nuevamente detenida y permaneció en esa condición por algunos días. Abocada al cuidado de sus pequeños, los primeros años de la democracia la mantuvieron replegada sobre el espacio familiar y, si bien realizó su denuncia ante la CONADEP, no tuvo en esos años una participación activa en el campo de los derechos humanos, aunque se convertiría en una referente del movimiento gremial docente. Avanzados los años 2000 fue electa legisladora de la Ciudad de Buenos Aires y en los últimos tiempos de la gestión kirchnerista se desempeñó al frente de los sitios de memoria.

18 Ello se plasma, incluso, en su ingreso a una universidad privada. Según señalaba, no había podido volver a la Universidad de Buenos Aires, donde había comenzado a estudiar luego de la escuela secundaria y antes de ser secuestrado.

$19 \mathrm{Al}$ igual que en otras historias se anuncia aquí no tan sólo la profunda ruptura sino también -aun cuando de manera menos evidente- la idea de una incipiente recomposición de un espacio propio; en su caso, plasmado en el apego a su grupo familiar, los estudios universitarios, y la revinculación con su novia de la adolescencia, ajena al mundo político.

20 Militante del peronismo de izquierda, Margarita fue secuestrada en el marco del Operativo Independencia y permaneció cautiva durante dos meses en lo que pudo identificar como el CCD "Escuelita de Famaillá". Tras su liberación, y con su pequeño hijo a cargo, se "insilió” en Buenos Aires. Allí nació su segundo hijo. Luego de años de profunda tristeza, la transición democrática propiciaría nuevos encuentros y recorridos que la vincularían con el campo de los derechos humanos. Actualmente es miembro de la Asociación de Ex Detenidos Desaparecidos y ha brindado su testimonio en múltiples instancias.

21 La decisión misma de partir a Buenos Aires - que en ningún momento parece haber sido suya sino de sus padres-, es evocada desde una fuerte ambigüedad: como un "castigo" por la exposición al peligro y, al mismo tiempo, como aquello que le salvó la vida.

22 Como he podido analizar en mi tesis, la inserción en la arena política había suscitado fuertes rupturas con ámbitos, instituciones y creencias. Los vínculos familiares - principalmente encarnados en las figuras de las madres y/o padres-, los estudios e, incluso, el credo religioso se vieron muchas veces sacudidos por estos nuevos universos de acción y sentido anudados a la práctica política.

23 Militante de la Juventud de Vanguardia Comunista, a mediados de julio de 1978 fue secuestrada y detenida en lo que tiempo después supo que era "El Vesubio". Tras dos meses de cautiverio, fue legalizada junto con otros detenidos y trasladada al Penal de Devoto hasta mayo de 1979. A partir de entonces, permaneció en un profundo retraimiento sobre su espacio privado, se casó y fue madre. A mediados de los años 90 asentó la denuncia de su caso para la tramitación de la reparación económica pero no fue sino hasta los años 2000 que su testimonio asumiría nuevos sentidos y recorridos. Desde entonces, Silvia participa en el campo de derechos humanos. 
Julieta Lampasona. “(Des)AParición y después. ENTre El ARrasamiento y La (Re)Construcción DE LOS E...

24 En efecto, nuestra entrevistada enfatizó no haber hablado en su casa acerca de su actividad política. Como veremos, el vínculo se verá resignificado luego de su legalización y, particularmente, del reencuentro con esos padres visible y físicamente devastados por su secuestro y búsqueda.

25 A comienzos de 1970 y mientras cursaba sus estudios secundarios, Laura había iniciado su militancia en la Unión de Estudiantes Secundarios (UES). A finales de mayo de 1976, ella y su madre fueron secuestradas y, según sus estimaciones, fue llevada en primer lugar al Regimiento Patricios y luego a lo que pudo identificar como "El Vesubio", donde permaneció unos días hasta concluir el recorrido en Campo de Mayo. Allí decidieron liberarlas, tras cinco días de cautiverio. Al poco tiempo, ella, su madre y su hermana partieron a un breve exilio, en la ciudad de Nueva York, y luego de que su madre y su hermana volvieron al país, viajó a Israel donde permaneció junto a su novio hasta volver a Argentina, meses después. Como veremos, los años posteriores a su regreso fueron de un marcado distanciamiento con su historia previa y así lo sostendría por largos años. Ya en los años 90 participó de diversas iniciativas vinculadas con la temática de derechos humanos y comenzó así a transitar nuevos espacios y formas de visibilidad, sin desplegar una militancia activa.

26 Retomando a Jelin (2002), el olvido aparece aquí como una forma de resguardo, como aquello que posibilita la propia vida con posterioridad a la situación límite.

27 En efecto, y como sucedía también en otros casos, cabe señalar que ese "terror" se solapaba indefectiblemente con el contexto dictatorial pero también, ya en democracia, con la posibilidad y/o amenaza de un nuevo golpe militar.

\section{BY-NC-SA}

